EXTENDED REPORT

\title{
Mortality of rheumatoid arthritis in Japan: a longitudinal cohort study
}

\author{
M Hakoda, H Oiwa, F Kasagi, N Masunari, M Yamada, G Suzuki, S Fujiwara
}

Ann Rheum Dis 2005;64:1451-1455. doi: 10.1136/ard.2004.033761

See end of article for authors' affiliations .....................

Correspondence to: Dr Masayuki Hakoda, Department of Clinical Studies, Radiation Effects Research Foundation, 5-2 Hijiyama Park, MinamiKu, Hiroshima 732-0815 Japan; hakoda@rerf.or.jp

Accepted 14 March 2005 Published Online First 5 May 2005

\begin{abstract}
Objective: To determine the mortality risk of Japanese patients with rheumatoid arthritis, taking into account lifestyle and physical factors, including comorbidity.

Methods: 91 individuals with rheumatoid arthritis were identified during screening a cohort of 16119 Japanese atomic bomb survivors in the period 1958 to 1966. These individuals and the remainder of the cohort were followed for mortality until 1999. Mortality risk of the rheumatoid patients was estimated by the Cox proportional hazards model. In addition to age and sex, lifestyle and physical factors such as smoking status, alcohol consumption, blood pressure, and comorbidity were included as adjustment factors for the analysis of total mortality and for analysis of mortality from each cause of death.

Results: 83 of the rheumatoid patients (91.2\%) and 8527 of the non-rheumatoid controls (52.9\%) died during mean follow up periods of 17.8 and 28.0 years, respectively. The age and sex adjusted hazard ratio for mortality in the rheumatoid patients was 1.60 (95\% confidence interval, 1.29 to 1.99 ), $p<0.001$. Multiple adjustments, including for lifestyle and physical factors, resulted in a similar mortality hazard ratio of 1.57 (1.25 to 1.94), $\mathrm{p}<0.001$. Although mortality risk tended to be higher in male than in female rheumatoid patients, the difference was not significant. Pneumonia, tuberculosis, and liver disease were significantly increased as causes of death in rheumatoid patients.

Conclusions: Rheumatoid arthritis is an independent risk factor for mortality. Infectious events are associated with increased mortality in rheumatoid arthritis.
\end{abstract}

$\mathrm{S}$ ince the first such report was published in 1953, numerous studies have investigated mortality in rheumatoid arthritis, and many of these have found an increase in mortality. ${ }^{1-29}$ Most of the studies compared the observed number of deaths among rheumatoid patients during the follow up period with the expected number of deaths calculated from census data. Although several lifestyle and physical factors such as smoking status, alcohol use, body mass index, and comorbidity can affect mortality, these factors were never included for control subjects in the analyses because the control data were always obtained from census data.

Mikuls et al were the first to take into account such lifestyle and physical factors in the analysis of mortality in rheumatoid arthritis. ${ }^{25}$ The researchers used the Iowa women's health study cohort and obtained potential confounding factors including smoking history, alcohol use, education level, body mass index, and comorbidity of four diseases (hypertension, heart disease, cancer, and diabetes). They found a significantly increased mortality risk among individuals with incidentally developed rheumatoid arthritis even after multiple adjustments for such factors. The cohort used in the study, however, comprised only women of older ages. Navarro-Cano et al followed 779 rheumatoid patients for 6.3 years and concluded that rheumatoid disease severity was significantly associated with mortality regardless of the presence of comorbid disease. ${ }^{30}$

To investigate whether rheumatoid arthritis is an independent risk factor for mortality, we analysed a Japanese cohort of atomic bomb survivors that has been followed up longitudinally for more than 40 years. We show here that the mortality risk of rheumatoid arthritis is significantly increased in both men and women compared with nonrheumatoid individuals, even after multiple adjustments for lifestyle and physical factors including comorbidity. This is the first report of mortality risk in Japanese patients with rheumatoid arthritis.

\section{METHODS}

\section{Study population}

The total study population is an atomic bomb survivor cohort, which was established in 1958 to investigate the long term effects of ionising radiation from the atomic bombs. ${ }^{31}$ The original cohort consisted of 19961 individuals, approximately half of whom were exposed to significant doses of ionising radiation from the atomic bombs proximally $(<2000$ $\mathrm{m}$ from the hypocentre). The other half of the cohort either were exposed distally ( $\geqslant 3000 \mathrm{~m}$ from the hypocentre) or were not in the city at the time of the bombings and thus were not substantially exposed to atomic bomb radiation. The subjects were followed longitudinally by biennial clinical examination at the Radiation Effects Research Foundation in Hiroshima and Nagasaki in Japan. This follow up study is named the adult health study and its detailed study design has been described elsewhere. ${ }^{31}$

Patients with rheumatoid arthritis were identified among this population during 1958-1966 using the American Rheumatism Association (ARA) diagnostic criteria for population studies. ${ }^{32}$ In all, 16119 individuals who came for clinical examination during this period were screened for rheumatoid arthritis, and 91 cases with definite or classical rheumatoid arthritis were identified..$^{33}$ There was no significant association between the prevalence of rheumatoid arthritis and radiation dose from the atomic bombs. ${ }^{32} 33$

\section{Baseline data}

All of the cohort members were invited to undergo clinical examinations every two years. Physical examinations including measurement of body weight, height, and blood pressure were carried out at each clinic visit. The participants were interviewed by nurses to obtain disease histories and lifestyle 
Table 1 Baseline characteristics of study population

\begin{tabular}{|c|c|c|c|}
\hline Variable & RA group & Non-RA group & p Value ${ }^{*}$ \\
\hline No of individuals & 91 & 16028 & \\
\hline Percent female & 80.2 & 61.5 & $<0.01$ \\
\hline Age (years) & 56.8 & 44.6 & $<0.01$ \\
\hline $\mathrm{BMI}\left(\mathrm{kg} / \mathrm{m}^{2}\right)$ & 21.3 & 21.2 & NS \\
\hline Current smoking (\%) & 16.7 & 36.5 & NS \\
\hline Alcohol use (g/week) & 2.5 & 2.9 & NS \\
\hline Radiation dose (Gy) & 0.36 & 0.37 & NS \\
\hline \multicolumn{4}{|l|}{ Comorbid disease (\%) } \\
\hline Hypertension & 29.7 & 27.5 & $<0.01$ \\
\hline Diabetes & 6.6 & 7.3 & NS \\
\hline $\mathrm{CHD}$ & 2.2 & 2.8 & NS \\
\hline Stroke & 3.3 & 1.8 & NS \\
\hline Anaemia & 34.1 & 20.3 & NS \\
\hline Kidney disease & 4.4 & 1.2 & $<0.05$ \\
\hline Liver disease & 2.2 & 2.3 & NS \\
\hline COPD & 14.3 & 10.7 & NS \\
\hline Cancer & 3.3 & 2.5 & NS \\
\hline \multicolumn{4}{|c|}{$\begin{array}{l}\text { The values for age, BMI, alcohol use, and radiation dose are the mean of each group. } \\
\text { *For the comparison between rheumatoid arthritis and non-rheumatoid arthritis individuals, adjustments were } \\
\text { made for age and sex except for the comparison of female percentage and mean age. } \\
\text { BMI, body mass index; CHD, coronary heart disease; COPD, chronic obstructive lung disease; RA, rheumatoid } \\
\text { arthritis. }\end{array}$} \\
\hline
\end{tabular}

information such as smoking status and drinking habits. The baseline for rheumatoid patients in the present study was the time of the clinic visit at which the diagnosis of rheumatoid arthritis was made during the period of screening for the disease (1958-1966). For non-rheumatoid individuals, the baseline was established as the time of the earliest clinic visit during the same period, with the aim of obtaining a conservative estimate of rheumatoid arthritis mortality risk.

\section{Mortality data}

Deaths were identified through checks on the status of all surviving cohort members, using the Japanese family registration system (koseki). The death data accumulated until March 1999 were used for the present analysis. No individual was lost during the follow up. Information on the underlying cause of death was obtained from death certificates and coded according to the International Classification of Diseases (ICD). Four ICD revisions were used depending on the time of death. Thus, the seventh, eighth, ninth, and 10th revisions (ICD 7, ICD 8, ICD 9, and ICD 10) were used for deaths during 1966-1967, 1968-1978, 19791997, and 1998-1999, respectively.

\section{Statistical analysis}

Cox proportional hazards models were used to estimate the mortality risk attributable to rheumatoid arthritis by adjusting for several variables at the baseline that were potential confounders for mortality risk. These variables included age, sex, smoking habits (never, former, current), alcohol use (g/ week), body mass index (BMI) $\left(\mathrm{kg} / \mathrm{m}^{2}\right)$, systolic blood pressure $(\mathrm{mm} \mathrm{Hg})$, total cholesterol level $(\mathrm{mg} / \mathrm{dl})$, estimated radiation dose (Gray), ${ }^{35}$ and comorbidity (yes/no). Baseline comorbid diseases taken into account were diabetes, hypertension, coronary heart disease (CHD), stroke, chronic liver disease, kidney disease, chronic obstructive pulmonary disease (COPD), tuberculosis, digestive ulcers, anaemia, and cancers. Similar analysis was undertaken to estimate mortality risk attributable to rheumatoid arthritis for each cause of death.

CHD, coronary heart disease; CI, confidence interval; RA, rheumatoid arthritis.

\section{RESULTS}

Characteristics of the study population at baseline are presented in table 1 . The female to male ratio in the rheumatoid patients was 4.1:1.0, while that of non-rheumatoid arthritis individuals was 1.6:1.0. The mean age of rheumatoid patients at baseline was 56.8 years, which was significantly higher than for the non-rheumatoid individuals (44.6 years). The mean duration of rheumatoid arthritis was 8.8 years. Although baseline data for physical activity were not available, rheumatoid factor positivity, $x$ ray findings in the hands and wrists, and erythrocyte sedimentation rate (ESR) were available for 80,75 , and 86 patients, respectively. The proportion of patients with positive rheumatoid factor was $78.8 \%$, and the proportion with radiographic bone erosion was $52.0 \%$. Mean ESR was $40.5 \mathrm{~mm} / \mathrm{h}$. BMI was not significantly different between the rheumatoid and nonrheumatoid groups. Although the proportion of current smokers tended to be lower in the rheumatoid than in the non-rheumatoid group, the difference was not statistically significant after adjustment for age and sex. Radiation dose from the atomic bombs did not differ between rheumatoid and non-rheumatoid individuals.

Table 2 Deaths observed up to March 1999

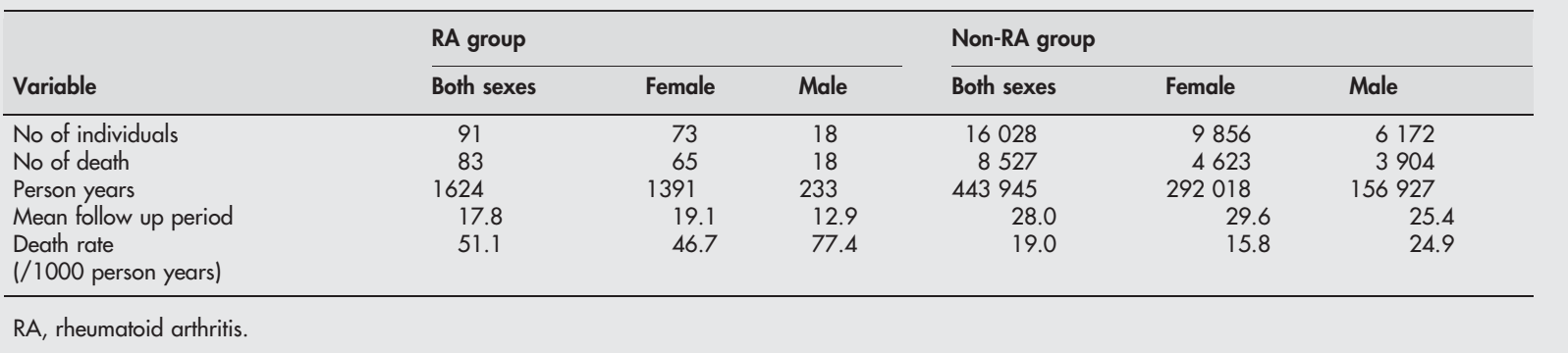


Table 3 Mortality risk of rheumatoid arthritis

\begin{tabular}{|c|c|c|c|}
\hline Adjustment & Hazard ratio & $95 \% \mathrm{Cl}$ & p Value \\
\hline \multicolumn{4}{|l|}{ Both sexes } \\
\hline Age, sex & 1.60 & 1.29 to 1.99 & $<0.001$ \\
\hline +Physical and lifestyle factors* & 1.57 & 1.25 to 1.94 & $<0.001$ \\
\hline \multicolumn{4}{|l|}{ Female } \\
\hline Age & 1.63 & 1.26 to 2.06 & $<0.001$ \\
\hline +Physical and lifestyle factors & 1.54 & 1.19 to 1.95 & $<0.001$ \\
\hline \multicolumn{4}{|l|}{ Male } \\
\hline Age & 1.40 & 0.85 to 2.15 & 0.157 \\
\hline +Physical and lifestyle factors & 1.83 & 1.14 to 2.82 & 0.011 \\
\hline
\end{tabular}

The prevalence of diseases other than rheumatoid arthritis at baseline is presented in table 1 . The proportion of individuals with hypertension appeared to be higher in the rheumatoid than in the non-rheumatoid population. However, after adjustment for age and sex, the proportion with hypertensive became significantly lower among the rheumatoid patients. This is probably because the prevalence of hypertension is age dependent and the mean age of the rheumatoid patients was greater than the mean age of the non-rheumatoid population. The prevalence of other diseases was also compared between the rheumatoid and nonrheumatoid populations after adjusting for age and sex (table 1). Although anaemia tended to be more prevalent among the rheumatoid patients, the difference was not statistically significant. Kidney disease was more prevalent among the rheumatoid patients than among the nonrheumatoid individuals. Significant differences between the rheumatoid and non-rheumatoid populations in prevalence at baseline were not observed for diabetes, coronary heart disease, stroke, cancer, chronic liver disease, or chronic obstructive pulmonary disease.

Up to March 1999, 83 deaths occurred among the 91 rheumatoid patients, whereas 8527 of the 16028 nonrheumatoid individuals died during the same period (table 2). Mean follow up was 17.8 years for rheumatoid patients and 28.0 years for the non-rheumatoid group. The death rate for the rheumatoid patients was 51.1 per 1000 person years, and for the non-rheumatoid group 19.0 person years.

Age and sex adjusted hazard ratio for mortality was 1.60 (95\% confidence interval (CI), 1.29 to 1.99 ), $p<0.001$, for the rheumatoid patients (table 3 ). Other adjustments were made for variables including physical and lifestyle factors, as described in Methods, were then further adjusted for the estimation of mortality risk. After these adjustments, the mortality hazard ratio for rheumatoid arthritis was 1.57 (95\% CI, 1.25 to 1.94 ), $\mathrm{p}<0.001$ (table 3 ).

Analysis restricted to the individuals without significant exposure to atomic bomb radiation (those distally exposed to the bombs or who were not in city at the time of the bombings) gave similar results. In all, 45 rheumatoid patients and 7927 non-rheumatoid individuals were included in this category, and the mortality hazard ratio was 1.80 (95\% CI, 1.29 to 2.42$)$ after multiple adjustments $(\mathrm{p}<0.001)$.

The mortality risk of rheumatoid arthritis was obtained for each sex separately. For women, the age adjusted mortality risk was 1.63 (95\% CI, 1.26 to 2.06 ), $\mathrm{p}<0.001$, and the fully adjusted risk was 1.54 (1.19 to 1.95 ), $p<0.001$, neither of which differed significantly from the values obtained for the group overall. For men, on the other hand, the age adjusted mortality risk was 1.40 (95\% CI, 0.85 to 2.15$), p=0.157$, and the fully adjusted mortality risk was 1.83 (95\% CI, 1.10 to $2.82), \mathrm{p}=0.011$. Although the fully adjusted mortality risk for the male rheumatoid patients seemed higher than for the female patients, the difference was not statistically significant.

The mortality risk of rheumatoid arthritis was analysed for each cause of death. Fully adjusted mortality risk results are presented in table 4 . When the causes of death were classified according to organ system, an increased mortality risk was observed only for respiratory diseases. Although the hazard ratios for death from cardiovascular disease, digestive tract disease, kidney disease, and infectious disease were all greater than 1.0, the increases were not statistically significant. No significant increase in mortality from cancers was observed in the rheumatoid patients. Subsequently, more specific organs and diseases were analysed, and it was found that the mortality risk in rheumatoid patients was

\begin{tabular}{|c|c|c|c|c|}
\hline \multirow[b]{2}{*}{ Cause of death } & \multicolumn{2}{|c|}{ No of deaths (\%) } & \multicolumn{2}{|l|}{ Mortality risk in RA } \\
\hline & $\overline{\mathrm{RA}}$ & Non-RA & Hazard ratio $(95 \% \mathrm{Cl})$ & p Value \\
\hline All causes & 83 & 8527 & 1.57 (1.25 to 1.94$)$ & $<0.001$ \\
\hline Cardiovascular & $29(34.9)$ & $3206(37.6)$ & $1.30(0.88$ to 1.84$)$ & 0.16 \\
\hline CHD & $5(6.0)$ & $646(7.6)$ & $1.26(0.45$ to 2.75$)$ & $>0.5$ \\
\hline Stroke & $15(18.1)$ & 1551 (18.2) & $1.34(0.76$ to 2.15$)$ & 0.27 \\
\hline Cancer & $12(14.5)$ & $2343(27.5)$ & $0.98(0.52$ to 1.66$)$ & $>0.5$ \\
\hline Digestive tract & $5(6.0)$ & $504(5.9)$ & $1.89(0.67$ to 4.11$)$ & 0.16 \\
\hline Liver & $4(4.8)$ & $249(2.9)$ & $4.53(1.38$ to 10.8$)$ & 0.003 \\
\hline Kidney & $2(2.4)$ & $192(2.3)$ & $1.66(0.27$ to 5.37$)$ & 0.49 \\
\hline Respiratory & $13(15.7)$ & $839(9.8)$ & $2.83(1.54$ to 4.71$)$ & $<0.001$ \\
\hline Pneumonia & $9(10.8)$ & 533 ( 6.3) & 2.97 (1.41 to 5.44$)$ & 0.001 \\
\hline Tuberculosis & $4(4.8)$ & $141(1.7)$ & $4.32(1.30$ to 10.6$)$ & 0.005 \\
\hline
\end{tabular}


Table 5 Baseline characteristics and mortality risk of rheumatoid arthritis

\begin{tabular}{|c|c|c|c|c|}
\hline Baseline factor & No of patients & Hazard ratio & $95 \% \mathrm{Cl}$ & $p$ Value \\
\hline \multicolumn{5}{|c|}{ Rheumatoid factor } \\
\hline Positive & 63 & 1.76 & 1.33 to 2.26 & $<0.001$ \\
\hline Negative & 17 & 0.85 & 0.49 to 1.34 & $>0.5$ \\
\hline \multicolumn{5}{|c|}{ Radiographic bone erosion } \\
\hline Present & 39 & 1.67 & 1.19 to 2.27 & 0.002 \\
\hline Absent & 36 & 1.38 & 0.94 to 1.94 & 0.078 \\
\hline \multicolumn{5}{|l|}{ ESR } \\
\hline$\leqslant 40 \mathrm{~mm} / \mathrm{h}$ & 48 & 1.68 & 1.24 to 2.21 & $<0.001$ \\
\hline$>40 \mathrm{~mm} / \mathrm{h}$ & 38 & 1.30 & 0.89 to 1.81 & 0.147 \\
\hline
\end{tabular}

significantly raised for liver disease, pneumonia, and tuberculosis.

Although baseline data for physical activity were not available for the rheumatoid patients, $x$ ray findings in the hands and wrists, rheumatoid factor positivity, and ESR values were available for 75,80 , and 86 patients, respectively. The effects of these baseline variables on mortality were analysed. As shown in table 5, the presence of bone erosions in the hands and wrists was associated with increased mortality compared with non-rheumatoid individuals. On the other hand, in patients without bone erosions, the increase in mortality was not significant. The presence of rheumatoid factor was associated with increased mortality in rheumatoid patients but mortality of patients without rheumatoid factor was not increased. ESR values of more than $40 \mathrm{~mm} / \mathrm{h}$ were also associated with higher mortality in rheumatoid patients, whereas lower ESR values were not.

\section{DISCUSSION}

In this study, rheumatoid arthritis mortality risk was measured using death data on both rheumatoid and nonrheumatoid individuals in a Japanese cohort that has been followed up longitudinally. Thus our study directly compared the mortality of patients with rheumatoid arthritis with that of non-rheumatoid individuals. This is in contrast with most previous studies in which control mortality was estimated from census data. In addition to age and sex, we also adjusted for several potentially important confounding factors, including smoking status, alcohol intake, body mass index, blood pressure, and comorbidities. Even after these adjustments, the mortality risk did not change substantially, suggesting that the increased mortality risk of rheumatoid arthritis does not reflect the confounding of other lifestyle and physical factors. Mikuls et al also adjusted for several confounding factors and observed a significantly increased mortality risk of rheumatoid arthritis in a prospective cohort of older women. ${ }^{25}$ These results confirm that rheumatoid arthritis is an independent risk factor for mortality.

We observed significantly increased mortality from pneumonia in the rheumatoid patients. We also found increased mortality from tuberculosis. In Japan, tuberculosis mortality until the early 1970s was five to 10 times higher than that during the 1990s according to the census data. As all deaths from tuberculosis in the rheumatoid patients in our cohort occurred before 1973, our present finding of increased mortality from tuberculosis may be related to Japan's high background tuberculosis mortality. Although information on drug usage was not available for the present cohort, the use of corticosteroids might have been associated with infectious events in the rheumatoid patients. Liver disease was also increased as a cause of mortality in the rheumatoid patients in our study. As aspirin and indomethacin were available in Japan at the baseline period of this study, such drugs may have played a role in the induction of liver disease in the rheumatoid patients. Methotrexate may be associated with liver toxicity, but the use of this drug in Japan became popular only in the mid 1990s, and most deaths in our rheumatoid cohort occurred before this. Jacobsson et al studied a cohort of Pima Indians and reported that the death rate from liver cirrhosis and other alcohol related diseases was increased in rheumatoid patients. ${ }^{14}$ Deaths from cardiovascular disease tended to be increased in rheumatoid patients in our study, but the increase was not statistically significant.

In addition to the availability of data on potentially confounding factors for mortality analysis, one of the strengths of our study is the long follow up period of over 40 years. During this follow up, more than $90 \%$ of the rheumatoid patients died. Other strengths include the prospective cohort design, population based setting, and complete coverage of information on health status. Limitations include the small number of rheumatoid patients, the lack of information on the physical activity and treatment of the rheumatoid patients, and the potential misclassification of causes of death obtained from death certificates. It is unlikely that radiation exposure influenced the results as the mean radiation dose in the rheumatoid and non-rheumatoid groups was similar. Furthermore, analysis restricted to the individuals without substantial exposure to atomic bomb radiation gave similar results.

Individuals who did not have rheumatoid arthritis at baseline may have developed it during the follow up period. However, as the non-rheumatoid group at baseline was large, the contribution of this factor is unlikely to have had an important influence on the results. Furthermore, if the individuals who developed rheumatoid arthritis during follow up had an increase in mortality similar to that shown for the group with the disease at baseline, our results may be a conservative estimate of the true mortality risk of rheumatoid arthritis in our cohort.

\section{Conclusions}

We showed that rheumatoid arthritis is an independent risk factor for mortality by adjusting for several potential confounding factors in a population based Japanese cohort. In Japan, no disease modifying antirheumatic drugs were commercially available until 1970, and the use of methotrexate only became popular in the 1990s. As our patients participated in the study between 1958 and 1966, our estimate of the mortality of rheumatoid arthritis may be a reflection of its natural course. Our data provide a basis for the evaluation of treatment strategies for rheumatoid arthritis in terms of improvement in mortality prognosis.

\section{ACKNOWLEDGEMENTS}

The Radiation Effects Research Foundation (RERF), Hiroshima and Nagasaki, Japan is a private, non-profit foundation funded by the Japanese Ministry of Health, Labour and Welfare (MHWL) and the US Department of Energy (DOE), the latter through the National 
Academy of Sciences (NAS). This report was supported by RERF Research Protocol (RP \#2-75).

\section{Authors' affiliations}

M Hakoda, H Oiwa*, N Masunari, M Yamada, G Suzuki, S Fujiwara,

Department of Clinical Studies, Radiation Effects Research Foundation,

Hiroshima, Japan

F Kasagi, Department of Epidemiology, Radiation Effects Research Foundation

*Current address: Department of Respiratory Diseases, National Hiroshima Hospital, 513 Jike, Saijo, Higashi-Hiroshima City, Hiroshima 739-0041, Japan

\section{REFERENCES}

1 Cobb S, Anderson F, Bauer W. Length of life and cause of death in rheumatoid arthritis. N Engl J Med 1953;249:553-6.

2 Duthie JJ, Brown PE, Truelove LH, Baragar FD, Lawrie AJ. Course and prognosis in rheumatoid arthritis. A further report. Ann Rheum Dis 1964;23:193-204.

3 Uddin J, Kraus AS, Kelly HG. Survivorship and death in rheumatoid arthritis Arthritis Rheum 1970;13:125-30.

4 Isomaki HA, Mutru O, Koota K. Death rate and causes of death in patients with rheumatoid arthritis. Scand J Rheumatol 1975;4:205-8.

5 Monson RR, Hall AP. Mortality among arthritics. J Chronic Dis 1976:29:459-67.

6 Lewis P, Hazleman BL, Hanka R, Roberts S. Cause of death in patients with rheumatoid arthritis with particular reference to azathioprine. Ann Rheum Dis 1980;39:457-61.

7 Allebeck P, Ahlbom A, Allander E. Increased mortality among persons with rheumatoid arthritis, but where RA does not appear on death certificate. Eleven-year follow-up of an epidemiological study. Scand J Rheumatol $1981 ; 10: 301-6$.

8 Allebeck P. Increased mortality in rheumatoid arthritis. Scand J Rheumatol 1982;11:81-6.

9 Prior P, Symmons DP, Scott DL, Brown R, Hawkins CF. Cause of death in rheumatoid arthritis. Br J Rheumatol 1984;23:92-9.

10 Pincus T, Callahan LF, Sale WG, Brooks AL, Payne LE, Vaughn WK. Severe functional declines, work disability, and increased mortality in seventy-five rheumatoid arthritis patients studied over nine years. Arthritis Rheum 1984;27:864-72.

11 Mutru O, Laakso M, Isomaki H, Koota K. Ten year mortality and causes of death in patients with rheumatoid arthritis. BMJ (Clin Res) 1985;290:1797-9.

12 Mitchell DM, Spitz PW, Young DY, Bloch DA, McShane DJ, Fries JF. Survival, prognosis, and causes of death in rheumatoid arthritis. Arthritis Rheum 1986;29:706-14.

13 Reilly PA, Cosh JA, Maddison PJ, Rasker JJ, Silman AJ. Mortality and survival in rheumatoid arthritis: a 25 year prospective study of 100 patients. Ann Rheum Dis 1990;49:363-9.

14 Jacobsson LT, Knowler WC, Pillemer S, Hanson RL, Pettitt DJ, Nelson RG, et al. Rheumatoid arthritis and mortality. A longitudinal study in Pima Indians. Arthritis Rheum 1993;36:1045-53.

15 Wolfe F, Mitchell DM, Sibley JT, Fries JF, Bloch DA, Williams CA, et al. The mortality of rheumatoid arthritis. Arthritis Rheum 1994;37:481-94.
16 Wallberg-Jonsson S, Ohman ML, Dahlqvist SR. Cardiovascular morbidity and mortality in patients with seropositive rheumatoid arthritis in Northern Sweden. J Rheumatol 1997:24:445-51.

17 Symmons DP, Jones MA, Scott DL, Prior P. Longterm mortality outcome in patients with rheumatoid arthritis: early presenters continue to do well. J Rheumatol 1998;25:1072-7.

18 Lindqvist E, Eberhardt K. Mortality in rheumatoid arthritis patients with disease onset in the 1980s. Ann Rheum Dis 1999;58:11-14.

19 Sokka T, Mottonen T, Hannonen P. Mortality in early "sawtooth" treated rheumatoid arthritis patients during the first 8-14 years. Scand J Rheumatol 1999;28:282-7.

20 Gabriel SE, Crowson CS, O'Fallon WM. Mortality in rheumatoid arthritis: have we made an impact in 4 decades? J Rheumatol 1999;26:2529-33.

21 Kvalvik AG Jones MA, Symmons DP. Mortality in a cohort of Norwegian patients with rheumatoid arthritis followed from 1977 to 1992 Scand J Rheumatol 2000;29:29-37.

22 Kroot EJ, van Leeuwen MA, van Rijswijk MH, Prevoo ML, Van't Hof MA, van De Putte LB, et al. No increased mortality in patients with rheumatoid arthritis: up to 10 years of follow up from disease onset. Ann Rheum Dis 2000;59:954-8.

23 Goodson NJ, Wiles NJ, Lunt M, Barrett EM, Silman AJ, Symmons DP. Mortality in early inflammatory polyarthritis: cardiovascular mortality is increased in seropositive patients. Arthritis Rheum 2002:46:2010-19.

24 Peltomaa R, Paimela L, Kautiainen H, Leirisalo-Repo M. Mortality in patients with rheumatoid arthritis treated actively from the time of diagnosis. Ann Rheum Dis 2002;61:889-94.

25 Mikuls TR, Saag KG, Criswell LA, Merlino LA, Kaslow RA, Shelton BJ, et al. Mortality risk associated with rheumatoid arthritis in a prospective cohort of older women: results from the lowa Women's Health Study. Ann Rheum Dis 2002;61:994-9.

26 Gabriel SE, Crowson CS, Kremers HM, Doran MF, Turesson C, O'Fallon WM, et al. Survival in rheumatoid arthritis: a population-based analysis of trends over 40 years. Arthritis Rheum 2003:48:54-8.

27 Thomas E, Symmons DP, Brewster DH, Black RJ, Macfarlane GJ. National study of cause-specific mortality in rheumatoid arthritis, juvenile chronic arthritis, and other rheumatic conditions: a 20 year followup study. J Rheumatol 2003:30:958-65

28 Watson DJ, Rhodes T, Guess HA. All-cause mortality and vascular events among patients with rheumatoid arthritis, osteoarthritis, or no arthritis in the UK General Practice Research Database. J Rheumatol 2003;30:1 196-202.

29 Minaur NJ, Jacoby RK, Cosh JA, Taylor G, Rasker JJ. Outcome after 40 years with rheumatoid arthritis: a prospective study of function, disease activity, and mortality. J Rheumatol Suppl 2004;69:3-8.

30 Navarro-Cano G, Del Rincon I, Pogosian S, Roldan JF, Escalante A. Association of mortality with disease severity in rheumatoid arthritis, independent of comorbidity. Arthritis Rheum 2003;48:2425-33.

31 Beebe GW, Fujiwara H, Yamasaki M. Adult Health Study reference papers, A: Selection of the sample; B: Characteristics of the sample. ABCC Technical Report 10-60. Hiroshima: Atomic Bomb Casualty Commission, 1960.

32 Kiellgren JH. Diagnostic criteria for population studies. Bull Rheum Dis 1962;13:291-2.

33 Wood JW, Kato H, Johnson KG, Uda Y, Russell WJ, Duff IF. Rheumatoid arthritis in Hiroshima and Nagasaki, Japan. Prevalence, incidence, and clinical characteristics. Arthritis Rheum 1967;10:21-31.

34 Kato H, Duff IF, Russell WJ, Uda Y, Hamilton HB, Kawamoto S, et al. Rheumatoid arthritis and gout in Hiroshima and Nagasaki, Japan. A prevalence and incidence study. J Chronic Dis 1971;23:659-79.

35 Roesch WC. Final report on US-Japan joint reassessment of atomic bomb radiation dosimetry in Hiroshima and Nagasaki. Hiroshima: Radiation Effects Research Foundation, 1987. 